\title{
The Effects of the Gamified Flipped Classroom Method on Petroleum Engineering Students' Pre-class Online Behavioural Engagement and Achievement
}

\author{
https://doi.org/10.3991/ijep.v11i5.21957 \\ Gulsum Asiksoy( $\left.{ }^{\bowtie}\right)$, Serhat Canbolat \\ Near East University, Nicosia, Turkey \\ gulsum.asiksoyeneu.edu.tr
}

\begin{abstract}
In the recent times, the flipped classroom method is used commonly in higher education where pre-class online activities have a vital role. However, one of the most significant issues is the lack of participation of the students in pre-class online activities. In this study, a Gamified Flipped Classroom (GFC) environment proposes a solution to this issue. A true-experimental design was used in the study and the effects of teaching in this environment on students' online behaviors and achievements were investigated. The participants were fourth-year undergraduate petroleum and natural gas engineering students enrolled in a natural gas engineering course. The experimental group students learned with the gamified flipped classroom (GFC) method, while the control group students learned with the conventional flipped classroom (CFC) method. Data were collected from a natural gas concept test (NGCT), weekly quizzes, and data logs from Moodle. The research results indicated that teaching in the gamified flipped classroom (GFC) method showed a significant increase in the students' participation in the pre-class activities of the flipped classroom compared to the control group. Moreover, there was a significant increase in the achievement levels of the experimental group as compared to the control group. The results of this study provide evidence that the use of gamification elements in the pre-class phase of the flipped classroom method not only enhanced the students' pre-course online behaviour but also significantly improved their achievement.
\end{abstract}

Keywords-flipped classroom, gamification, higher education, online behavior

\section{$1 \quad$ Introduction}

Teaching in higher education is achieved through the traditional method, where the transfer of knowledge is carried out by the lecturers. However majority of students who have been educated by traditional methods do not have the sufficient skills for a successful career. [1]. To improve the quality of education and prepare students better for successful careers, new methods such as flipped classroom can be effectively used [2].

The flipped classroom (FC) is a rapidly evolving pedagogical method consisting of both pre-class and in-class activities [2]. In this method, the instructor delivers the course content with videos and various online materials. The students watch the lecture videos before coming to class. In the class, activities that encourage the participation of 
the students, such as problem solving and discussions, are carried out [3]. One of the most important problems of FC implementation is that students do not spend time on online pre-classroom learning activities and come to class with inadequate knowledge [4]. In this case, the unprepared students will not be active in-class activities and their performances will negatively be affected [5].

To overcome this problem, researchers suggest different strategies. The most commonly used strategy is the implementation of mini-quizzes at the end of the online practice or the beginning of the class hour [6]. Another way of ensuring that students watch the videos is to add questions into these videos [7]. A different strategy is to include pre-class online activities to a portion of their grade [8]. There is no single formula to ensure that the students come to class prepared and the design factors that increase students' online participation should be known.

In education, using a gamification strategy could be an effective tool to increase student engagement and learning compared to the traditional methods [9]. Gamification can be defined as the application of game-like mechanics to non-game situations or contexts [10]. According to another definition, gamification is a system that changes the behaviour of people by applying game design elements to non-game contexts. The main purpose of gamification is to motivate users to perform certain activities [11].

In the literature, limited studies have examined the effects of using gamification with the flipped classroom method [4]; [12]; [13]. However, they have investigated the effects of gamification in the in-class phase of the FC. In the literature, no studies have specifically investigated the effects of gamification on the pre-class phase.

Therefore, this study aims to investigate analyze whether the gamification strategy will be effective on students' participation in pre-class learning activities. For this purpose, the study seeks to answer the following research questions:

1. What is the effect of the Gamified Flipped Classroom Method on students' online behavioural engagement in the pre-class activities?

- The time spent in an online environment by the groups

- The number of messages sent by the groups to the online forum.

- The number of students who complete the weekly quizzes in both groups.

- The number of students' who watched the videos in both groups.

2. What is the effect of the Gamified Flipped Classroom Method on students' achievement?

- Weekly pre-class quiz scores of the both groups.

- Whether there is a significant difference between both of the groups' Natural Gas concept (NGCT) post-test scores.

The paper is organized as follows: Section 2, reviews studies on gamification and the use of gamification in flipped classrooms. Section 3 presents the methodology of this research which provides information about research design, participants, data analysis, instructional design, the Gamified Environment that has been developed, as well as data collection tools. Section 4 describes implementation results. Section 5 concludes 
and discusses the study that is presented within this paper. In the last section limitations as well as future research plans are discussed.

\section{$2 \quad$ Literature review}

\subsection{Gamification}

Gamification is used in non-game situations in order to ensure that students learn through motivation and loyalty with game thinking, aesthetics, and game mechanics [14]. Gamification strategy is the most common context for experimental research in the field of education and learning [15]. With the increasing use of the gamification strategy in the field of education, it can be said that the use of the gamification strategy is also increasing in online courses and virtual learning environments [16].

The components of gamification are points, badges, levels, experience points (XP), and leaderboards. Additionally, some of the dynamics that reflect the users' interaction with the system are rescue, cooperation, exchange, advancement, and relationships. Mechanisms such as challenges, competitions, operations, changes, cooperation, feedback, winning an award, ranks, and notifications are the elements that keep students engaged in the system [17].

The results of the studies on the effects of gamification on learning outcomes in elearning environments have shown that this strategy increases the motivation towards the course, as well as the success and participation. For example, Stamatios Papadaki [18] applied the combined use of App Inventor and the game development method in a Computer Science course and assessed students' achievement and motivation in basic programming skills. The results of the study showed that the game development method increased students' motivation and basic programming success [19].

In another study conducted with high school students, the effect of game elements in the gamification strategy on students' knowledge, and engagement was examined. The study demonstrated that the overall productivity of students could be improved when leaderboards are used therefore it could be worth implementing it in classroom. Böckle et al [20], conducted a systematic literature review in order to understand the functioning of adaptive gamification and the presented solutions. In this study, 43 studies were analysed. According to the results of the research, the researchers identified five research difficulties and made suggestions for researchers who intend to conduct studies in this field. The research indicates that adaptive gamification in the field of gamification in particular has become an increasingly studied field in terms of ensuring the long-term loyalty of the learners.

Gil, Cantador, and Marczewski studied the mechanics and the circumstances of the player types in the e-learning environment. In the study, the gamification mechanics were combined with numerous learning activities, and their functions in the e-learning system, their effectiveness in learning, their connections between the mechanics, and the types of players associated with them were all analysed. According to the results of the research, learners who conformed to the achiever, socialized, and philanthropist 
player types were found to do the activities easier; however, the explorer player type learners seemed to be more ineffective in the learning activities [21].

Considering the effect of the gamification strategy in the literature on e-learning environments, it has commonly been assumed that teaching in an appropriate flipped classroom environment is a beneficial learning approach for increasing students' participation in online activities.

\subsection{Gamification and Flipped Classroom (FC)}

The strategy of gamification of in-class activities in FC implementations could be an efficient method. However there is only a limited number of studies in the literature examining gamification elements in the application of the FC method. Some of them have the strategy of gamification in the in-class phase of the flipped classroom. For instance, Latulipe, Long and Seminario carried out the teaching of a computer science course by integrating the flipped classroom method into the in-class phase by using the gamification strategy combined with teamwork. The results showed that students achieved higher final grades than in previous years. However, the specific factors (flipped classroom, teamwork or gamification) that led to better performance were not stated in the study [22].

A research was conducted to examine how educational science students' learning and motivation affected by a gamified flipped classroom intervention. The results showed the benefits of gamification on learning efficiency. The study further reported favourable effects of gamified in-class activities on intrinsic motivation and social relatedness, however no crucial effect was observed on competence need satisfaction. [12]. Hung, used the Kahoot application in class to evaluate students on an undergraduate English course carried out with the flipped classroom approach. The usage of gamification in this application was limited to the face-to-face session of the flipped classroom. In other studies, gamification elements were used in both pre-class and in-class phases of the flipped classroom method [23]. For instance, Yildirim, integrated the gamification elements into both the pre-class and in-class phase of the flipped classroom in the teaching of a Principles and Methods course to second grade Mathematics teaching students. He used points, badges, levels, experience points and leaderboards in the course, which was opened on the Moodle system. According to the results of the study conducted using a true experimental design, it has been determined that the flipped classroom method based on gamification had a positive effect on students' success and attitudes towards the course [24]. A study stated that the artefacts produced by the experimental group students using the gamification strategy and the self-determination theory based on flipped classroom method were of better quality than the artefacts of the control group students in which only the FC applied [11]. Measles and AbuDawood, analysed the game and learning processes by examining the relationships between gamification, learning and games in their literature-based study. They emphasized the use of this strategy in e-learning environments could have a helpful effect on the students' engagement and motivation [25]. 
In response to the present research gap, this research will contribute to the literature in terms of the problem of students coming to the classroom without suitably preparing the pre-class materials in the application of the flipped classroom method to the course.

In this context, the study analyses students' participation in pre-class tasks by integrating the gamification elements into the activities in the pre-class phase of the flipped classroom.

\section{Methodology}

\subsection{Research design}

A pre-test and post-test experimental design with a control group were used. The students were randomly assigned into groups. While the experimental group students were taught with the gamified converted classroom (GFC) method, the control group students were taught with the conventional flipped classroom (CFC) method. The experimental procedure is shown in Figure 1.

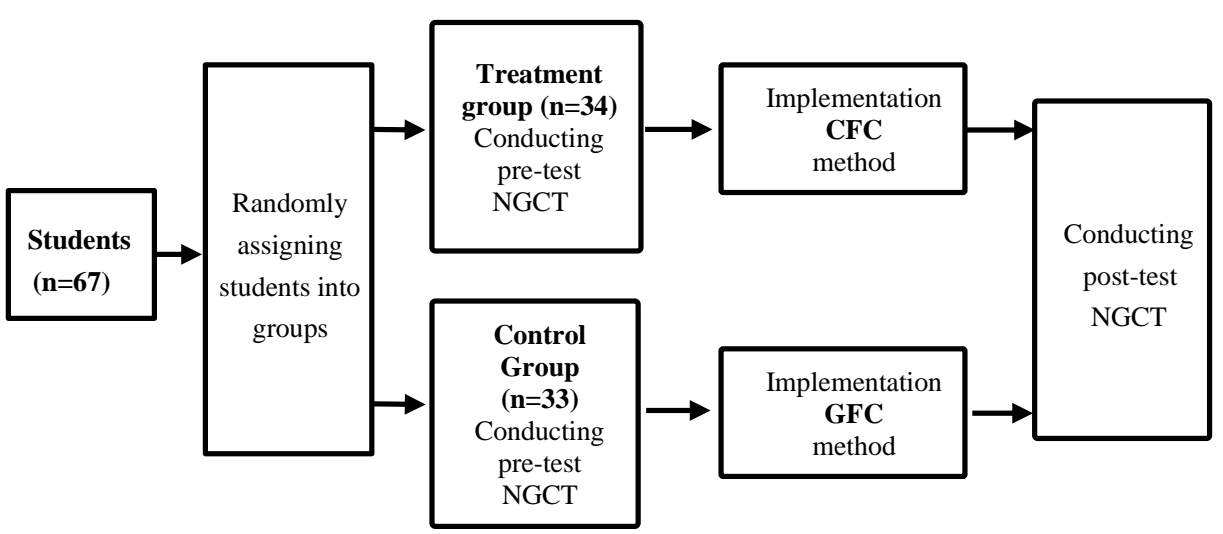

Fig. 1. The Research Design

\subsection{Participants}

The participants comprised 67 ( 22 females and 45 males) fourth-year undergraduate petroleum and natural gas engineering students enrolled in a natural gas engineering course at a private university during the fall term of 2019. The experimental group $(n=34)$ used the GFC method while the control group $(n=33)$ used the CFC method. All participants in the experimental and control groups were between 21 and 25 years of age. The same instructor taught both groups. Both groups used the university's Moodle platform. Each class was delivered for a total of 9 weeks.

Before the experimental implementation, Natural Gas Concept Test (NGCT) was applied as a pre-test to determine whether the students of both groups were equal in terms of natural gas engineering knowledge. Independent sample t-test results according to the NGCT pre-test results are shown in Table 1. 
Table 1. The pre-test of NGCT

\begin{tabular}{|l|c|c|c|c|c|}
\hline Group & $\mathbf{N}$ & Mean & SD & $\boldsymbol{t}$ & $\boldsymbol{p}$ \\
\hline Experimental & 34 & 44.85 & 12.09 & 1.997 & 0.960 \\
\hline Control & 33 & 44.69 & 13.69 & & \\
\hline
\end{tabular}

Statistical results determined that the natural gas concept knowledge pre-test results did not show a significant difference between the groups $(t=1.997, \mathrm{p}>0.05)$. This finding indicates that before implementation both groups had equal knowledge of natural gas concepts.

\subsection{Data analysis}

In the data analysis, basic descriptive statistics (the number of frequencies $-n$ ) and independent t-test were conducted to analyze the data. The significant level was considered as $\mathrm{p}<0.05$. All statistical analyses were done with SPSS program version 24.

\subsection{Instructional design}

Separate course pages for both groups were created by the researchers in the Moodle learning management system. Students entered the course with their username and password. Before the experiment procedure began, the control group was informed about how the courses were going to be carried out with the flipped classroom without gamification strategy (CFC method). Furthermore, the experimental group was informed about how the course was going to be carried out with the gamified flipped classroom (GFC). While one student in the control group had the experience of online learning, two students had such experience in the experimental group.

The Moodle course pages for both groups were enriched with events such as forums, instant messaging, feedback, and quizzes. In addition, the experimental group course page was enriched with gamification components through gamification plug-ins. The gamification components were not used in the control group's course page.

The students of both groups decided for themselves whether to complete the out-ofclass activities or not. The purpose of giving students this chance is to compare the experimental group students using the gamification strategy with the control group that does not use gamification in terms of completing their out-of-class activities.

The course contents of the two groups were the same for 9 weeks (Table 2). Both groups also attended class once a week (90 min.) on different days. Ethical approval was obtained from the university before implementation. 
Paper-The Effects of the Gamified Flipped Classroom Method on Petroleum Engineering Students'..

Table 2. Topics taught to the experimental and control group students by weeks

\begin{tabular}{|l|c|}
\hline Week & Topic \\
\hline 1 & Definition and components of natural gas, processing of natural gas \\
\hline 2 & Review of gas properties compressibility, formation volume \\
\hline 3 & Natural gas hydrates \\
\hline 4 & Water content of natural gas \\
\hline 5 & Gas reservoirs volumetric method, material balance method calculations \\
\hline 6 & Gas reservoirs, water influx, water influx models example \\
\hline 7 & Gas flow in porous media, deliverability tests \\
\hline 8 & Natural gas measurement, gas gathering and transport \\
\hline 9 & \\
\hline
\end{tabular}

Control Group. The courses in the control group were taught with the conventional flipped classroom (without gamification).

Before Class - For the control group, two days before the course, a video prepared by the researchers with a length of 15-20- mins and a quiz related to the course were uploaded to the Natural Gas Engineering course that had been created on Moodle. Students watched the videos at home and write questions about the parts they couldn't understand. In the forum module of the control group, students exchanged ideas about the topic.

During the class-Students discussed the parts they did not understand during the class time. Meanwhile, the instructor guided the discussions and made the necessary explanations to prevent false learning. Furthermore, problem-solving activities were carried out on the subject. The gamification components were not used when applying the flipped classroom method in the control group.

Experimental Group. It is stated in the literature that it is important to explain what the students will be doing and the reason why they are going to do it in the game environments [26]. Therefore, a clear explanation was given to the experimental students who were going to use the flipped classroom method together with the gamification strategy. However, in order to prevent students from constantly aiming to score points, the information on the scores of the tasks was kept confidential. The guidelines containing the information explained by the instructor were added to the Moodle course page. Figure 2 shows the structure of the experimental group.

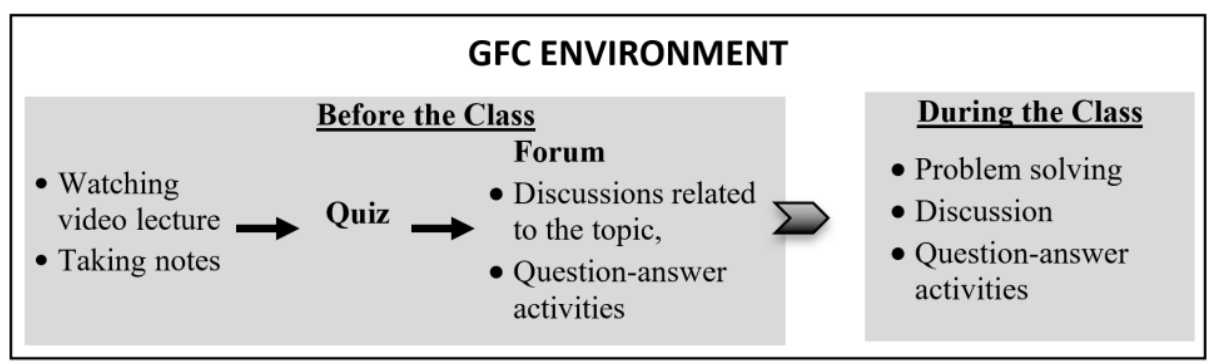

Fig. 2. The experimental group study design 
Before Class-The course videos and quizzes uploaded for the control group each week were sent to the course page of the experimental group two days before the course. Students watched the videos and took notes. They prepared questions on the parts they did not understand. The first student who watched the whole course video and completed the sent quiz correctly each week was given a petroleum engineering badge. Moreover, a helper badge was given to the student who gave quality answers to the other students in the forum and also participated in the discussions.

During the class-In class, students asked each other the parts about the parts they did not understand in the course video. Meanwhile, the instructor guided the discussions in order to prevent false learning and made the necessary explanations. Furthermore, problem-solving activities were carried out on the subject.

\subsection{Gamified Environment}

The Time Spent in Online Environment. To determine the time participants spent in the online environment, the "block configurable_reports" plug-in was used on Moodle. The plug-in enables data and time reports on the start and finishes times of any action of the user to be generated. The data obtained with this plug-in was converted into seconds and the time spent online of the experimental and control group participants were compared.

Badge. Badges are used for feedback purposes to reward the behaviours of the participants and also to identify their positions in the virtual environment [27]. Two different badges were used in the study. Firstly, the first student who watched the course video every week and completed the quiz correctly earned a petroleum engineering badge. Secondly, the student who helped the most in the forum and participated in the discussions earned a helper badge.

Experience Point. Moodle's "XP-Experience Point (block_xp)" plug-in was used for the GFC experiences of the students'. The students earned experience points by sending quality messages to the forum before the class regarding the subject. When the students shared a post regarding the objectives of the course, they earned 40 experience points and they earned 10 experience points when they read the posts. Experience points were effective in improving the student's level, moving them up the leaderboard and winning the helper badge.

Leaderboard. It is stated in the literature that the leaderboard is a powerful tool used to encourage students [28]. A leaderboard was created according to the points earned by the students in order to compare their achievements with the achievements of their friends. Only the names of the top 3 students of the week were written on the leaderboard.

Level. It is recommended that students are given feedback on the experience they gain in the gamified environment and that their progress is shown in the gamified system [14]. For this reason, the levels were formed based on the experience points and the scores obtained from the quizzes. Students were considered to be at Level 1 when they first signed in to the system and they remained at that level until they reached 500 points. The levels, the required experience points to reach those levels, and explanations have been given in Table 3 . 
Paper-The Effects of the Gamified Flipped Classroom Method on Petroleum Engineering Students'..

Table 3. Levels and the required experience points

\begin{tabular}{|l|c|c|}
\hline Levels & Titles & Experience points \\
\hline 1 & Junior engineer & 500 \\
\hline 2 & Senior engineer & 1000 \\
\hline 3 & Lead engineer & 3000 \\
\hline 4 & Head engineer & 8000 \\
\hline 5 & Manager & 13000 \\
\hline
\end{tabular}

Instant Feedback. In the literature, it has been stated that it is important to give feedback to the students and show their progress on the experience they have gained in the gamified environment in order to direct them to the intended behaviours [27]. Therefore, the gamification elements used in the study were badge, experience point, leaderboard, level, and feedback (Table 4).

Table 4. Gamification elements used in the GFC

\begin{tabular}{|l|l|}
\hline Element & \multicolumn{1}{|c|}{ Criteria } \\
\hline $\begin{array}{l}\text { Petroleum } \\
\text { Engineer Badge }\end{array}$ & $\begin{array}{l}\text { The first student who watched the video every week and completed the quiz correctly } \\
\text { earned the petroleum badge. }\end{array}$ \\
\hline Helper badge & $\begin{array}{l}\text { Helper badge was given to the student who was the most helpful in the forum before } \\
\text { the class time and to the student who participated in the discussion. }\end{array}$ \\
\hline Experience Points & $\begin{array}{l}\text { The student who made a quality post to the questions in the forum earned } 40 \text { points. } \\
\text { Students who read the forum messages earned 10 points. } \\
\text { There was no scoring in the second posts which had the same content. }\end{array}$ \\
\hline Leaderboard & $\begin{array}{l}\text { The top 3 students of the week were announced at the end of the week on Moodle. It } \\
\text { was used for the students to track their own learning progress, compare their perfor- } \\
\text { mance with their peers and to increase the competition. }\end{array}$ \\
\hline Level & Levels were formed according to the experience points. \\
\hline
\end{tabular}

\subsection{Data collection tools}

The Pre-class activity data (Time spent in online environment, the number of messages posted in the online forum before the class time, watching the course video weekly and weekly quiz completion) of the students' from both groups, which had to be completed before the deadline, were analysed in order to answer the research questions about online behavioural engagement. For the Achievement research question, the quiz scores and NGCT post-test (50\%) scores of each group of students were compared (Table 5).

Natural Gas Concept Test (NGCT). The NGCT was developed by a lecturer in the Petroleum and Natural Gas Engineering Department. The test, consisting of 22 multiple choice questions, was created on the subjects to be taught. There were five options for each question. The concept test was examined by three lecturers from the Petroleum and Natural Resources Department in order to ensure validity. According to the opinions of the experts, two questions were removed from the test and the total number of items was reduced to 20 . 
The NGCT test was used as a pre-test before the experimental process to determine whether the knowledge of the students of both groups were equal. It was also used as a post-test to compare the success of the groups at the end of the experimental process (after 9 weeks).

Weekly Quiz. Quizzes were sent together with the course videos in order to evaluate whether they understood the content of the videos or not. Each quiz consisted of 5 multiple choice questions, which were each assigned 1 point. Students who answered all of the questions in the weekly quiz correctly were awarded 5 points students who answered all of the questions incorrectly did not get any points. The scores obtained from the quizzes were effective as an indicator of the students' achievement and in earning Petroleum Engineer badge.

Table 5. Measures for online behaviour engagement, and achievement

\begin{tabular}{|l|c|}
\hline Dependent variable & Indicators \\
\hline \multirow{3}{*}{$\begin{array}{l}\text { Students' online } \\
\text { behaviour engagement }\end{array}$} & The time spent in the online environment \\
\cline { 2 - 2 } & The messages posted in the online forum \\
\cline { 2 - 2 } & Watching the course videos weekly \\
\cline { 2 - 2 } Students' achievement & Weekly quiz completion \\
\cline { 2 - 2 } & Weekly pre-class quiz scores $(50 \%)$ \\
\hline
\end{tabular}

\section{Results}

\subsection{Students' online behaviour engagement}

The time spent in online environment. The records of the time spent in the online environment by the two groups of students were kept and converted into second. The descriptive findings of the mean time (s) spent by the groups in the online environment have been presented in Table 6 .

Table 6. Descriptive and t-test findings related to time spent online.

\begin{tabular}{|l|c|c|c|c|c|}
\hline Group & $\mathbf{N}$ & Mean & SD & $\boldsymbol{t}$ & $\boldsymbol{p}$ \\
\hline Experimental & 34 & 8858.82 & 2787.21 & 1.997 & 0.000 \\
\hline Control & 33 & 4305.45 & 3008.35 & & \\
\hline
\end{tabular}

Significant at the 0.05 level.

The mean times spent by the groups were examined with a t-test for independent samples and a significant difference was found in favor of the experimental group $(\mathrm{t}=1.997, \mathrm{p}<0.05)$. Based upon these findings, it can be said that gamification increases the time spent by students in the online environment.

The number of messages posted in the online forum. The number of messages sent to the online forum found on the course pages was used as an indicator of the behavioral engagement of students in both groups. The descriptive findings of the high- 
Paper-The Effects of the Gamified Flipped Classroom Method on Petroleum Engineering Students'..

quality messages for the content that the groups sent to the online forum are presented in Table 7.

Table 7. Descriptive and t-test findings regarding messages posted

\begin{tabular}{|l|c|c|c|c|c|}
\hline Group & $\mathbf{N}$ & Mean & SD & $\boldsymbol{t}$ & $\boldsymbol{p}$ \\
\hline Experimental & 34 & 7.02 & 1.62 & 2.002 & 0.000 \\
\hline Control & 33 & 4.90 & 2.36 & & \\
\hline
\end{tabular}

Significant at the 0.05 level.

The number of messages sent by the groups to the online forum was examined with a t-test for independent samples and a significant difference was found in favor of the experimental group $(\mathrm{t}=2.002, \mathrm{p}<0.05)$. Based upon these findings, it can be said that gamification increases the number of messages posted on an online forum by students.

Weekly number of watching videos. As previously mentioned, the natural gas engineering course lasted for 9 weeks. Course videos that explained the course subjects were sent to both of the groups each week for nine weeks. The number of students who watched the videos before the deadline has been presented in Figure 3.

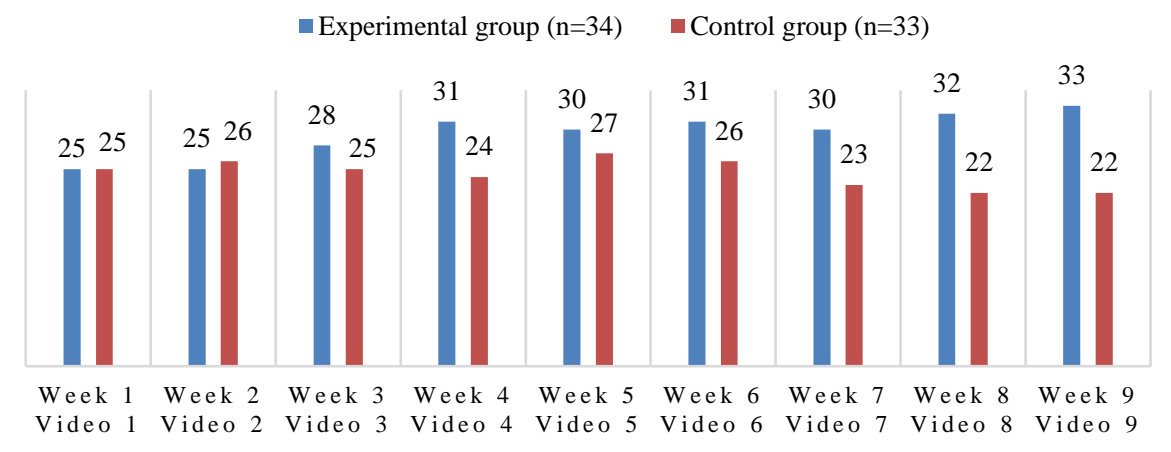

Fig. 3. The number of students who watched the videos before the weekly deadlines

According to Figure 3, the number of students who watched the course videos each week for 9 weeks was greater in the experimental group than in the control group. The number of students $(n=25)$ who watched the videos in both of the groups in the first week was the same. On the other hand, from the 3rd video onwards (3rd week), differences began to appear. While the number of students who watched the video before the deadline on the last week (9th week) was $n=33$ in the experimental group, in the control group, $n=22$ students watched the video. The descriptive data showed that as the weeks passed, the number of students who watched the videos increased in the experimental group and decreased in the control group.

Weekly quiz completion. The natural gas engineering course lasted for 9 weeks. Quizzes were sent to each group each week for 9 weeks related to their course subjects. The number of students in the experimental and control groups who completed the weekly quizzes before the deadline has been presented in Figure 4. 


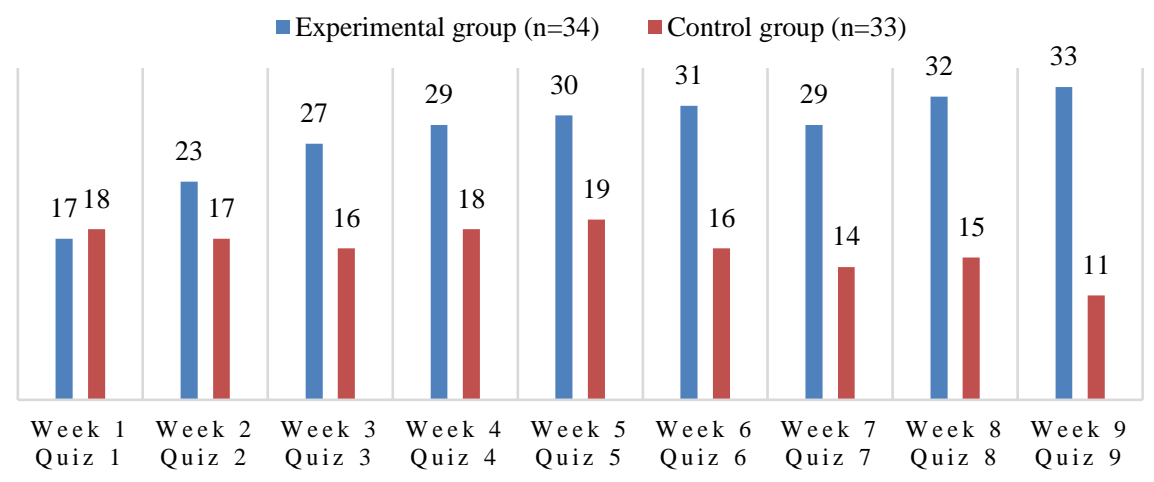

Fig. 4. The number of students who completed the quizzes before the weekly deadlines

As can be seen in Figure 4 the number of students who completed the quizzes for 9 weeks before the class time was higher in the experimental group than in the control group. The number of students who completed the quiz in the first week in each group was similar: experimental group $(n=17)$ and control group $(n=18)$. However, the differences became apparent beginning from Quiz 2. In the last week (9th Week), the number of students in the experimental group who completed the quiz before the deadline was $n=33$, while in the control group, it was $n=11$. The descriptive data showed that as the weeks passed, the number of students completing the quiz before the deadline increased in the experimental group and decreased in the control group.

\subsection{Students' Achievement}

Natural gas concept (NGCT) post-test scores. In the study, NGCT was used as a post-test to determine whether there were any changes in the level of knowledge of both groups after the experimental process completed. An independent sample t-test was conducted on the NGCT post-test results of both groups (Table 8).

Table 8. Descriptive and t-test findings related to time spent online.

\begin{tabular}{|l|c|c|c|c|c|}
\hline \multicolumn{1}{|c|}{ Group } & N & Mean & SD & t & p \\
\hline Experimental & 34 & 60.73 & 14.83 & 1.997 & 0.003 \\
\hline Control & 33 & 49.54 & 15.23 & & \\
\hline
\end{tabular}

Significant at the 0.05 level.

The statistical results revealed that the results of the natural gas conception knowledge post-test significantly differed between the control and the experimental groups $(\mathrm{t}=1.997, \mathrm{p}<0.05)$. According to this result, it can be concluded that the integration of the gamification elements into the pre-class stage of the flipped classroom method can have a positive effect on the students' achievements.

Weekly pre-class quiz scores. Students completed the quizzes that were prepared in relation to the course subject each week after watching the course video. In this way, 
the student's understanding of the contents was assessed. The quizzes consisted of 5 questions and each question was awarded 1 point. The students who answered all the questions correctly received 5 points. The scores of the students who did not take the exam were evaluated as missing data for each group. Both the control and experimental groups' scores were collected and analysed. A comparison of the weekly quiz scores for the quizzes completed before the deadline for both the experimental and control groups has been presented in Figure 5.

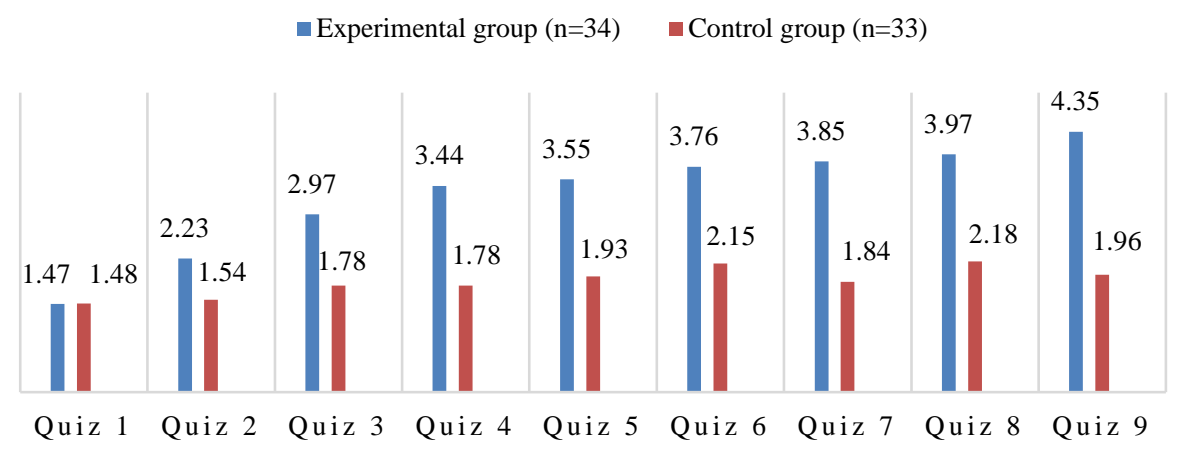

Fig. 5. Weekly pre-class quiz scores before the deadlines.

As can be seen in Figure 5, the quiz scores of the experimental and control group students in the first week were very close. However, while the score for the control group was 1.54 in the second week, the score for the experimental group was 2,23. In week nine, the quiz score of the experimental group was 4.35 and it was 1.96 in the control group. The descriptive data showed that as the weeks passed, the quiz scores increased in the experimental group and decreased in the control group.

An independent sample t-test was conducted to analyse whether statistically significant differences were between the experimental and control groups (Table 9).

Table 9. Weekly pre-class quiz scores

\begin{tabular}{|l|c|c|c|c|c|}
\hline Group & $\mathbf{N}$ & Mean & SD & $\boldsymbol{t}$ & $\boldsymbol{p}$ \\
\hline Experimental & 34 & 3.28 & 0.91 & 2.262 & 0.001 \\
\hline Control & 33 & 1.84 & 0.23 & & \\
\hline
\end{tabular}

Significant at the 0.05 level.

The results of the weekly pre-class scores significantly differed between both groups $(t=2.262, p<0.05)$. According to the results, the gamification elements integrated into the pre-class stage of the flipped classroom method had a positive effect on making the students solve the questions in the quiz correctly. 


\section{$5 \quad$ Discussion and conclusions}

The study investigated the effect of the gamification elements that were integrated into the pre-class phase activities of the flipped classroom method on the students' online behaviour engagements and achievements.

Students' online behaviour engagement. The research results have shown that integrating the gamification elements in the pre-class phase of the flipped classroom method had a positive effect on the students' online behaviours. Pre-class activity data that were analysed included students' time spent in the online environment, the number of messages posted on the online forum before the class time, the number of students watching the weekly course video, and weekly quiz completion numbers.

According to the findings of the study was a significant increase in the number of messages posted in online forums, number of students watching the videos weekly, and weekly quiz completion numbers in the experimental group compared to the conventional group. Furthermore, it has been identified that the experimental group students spent more time in the online learning environment compared to the control group students.

In the current study, some elements may have encouraged students to complete their tasks on time and accurately. This result is in line with research demonstrating students participate in learning activities [29]. Badges sent as feedback to students completing their tasks on time and correctly may have strengthened their behaviours. A study stated in their study that students felt good and they began to work more in the pre-class and post-class activities when they received positive feedback (e.g., badges) [30]. Given the view of Robinson and Bellotti that badges trigger a sense of curiosity, the badges used in the study are thought to have affected students' online participation positively [31].

Another gamification element that increased the experimental group students' online participation could have been the experience points. The experience point might have led to competition due to the possibility of students' increasing their level and being listed on the leaderboard. This finding is compatible with the view of Song et al which suggests that competition encourages individuals to work harder. However, some studies in the literature suggest that leaderboards can lead to negative competition among learners and may adversely affect the motivation of those in the lower ranks [32]; [26]. In our study, the leaderboard was used to give feedback to individuals. Only the top 3 students' names were written on the leaderboard each week. Thus, the students' in the lower ranks were prevented from losing motivation. On the other hand, feedback was sent to each student regularly via Moodle as a private message. According to Werbach and Hunter, each individual can be motivated by following his/her own development [27]. Therefore, the game elements, leaderboard, badges, experience points, and levels were used in our study to give feedback to the students. This finding is consistent with the findings of prior studies [33]; [12] who suggested that gamification positively affects online participation. Similarly, Amriani et al. stated in their study that including gamification in the environment increases online participation, whereas exclusion from the environment decreases online participation [34]. Furthermore, this parallels with results from Kalogiannakis, Papadakis, and Zourmpak's study, which determined that 
the learning outcomes that students were most affected by were motivation, participation, and, achievement. [35]

Students' achievement. According to another result of this study, it has been shown that the integration of the gamification elements into the flipped classroom methods' pre-class phase had a positive effect on the students' achievements. It has been identified that the NGCT post-test and weekly quiz scores of the experimental group who were using the gamified flipped classroom method were higher compared to the control group.

In the flipped classroom method, the fact that students came to the class prepared after performing the pre-class activities might have facilitated deeper learning in the classroom. This result is in line with the idea that incorporating the gamification strategies of Landers' into the teaching process allows students to use their time more efficiently on the relevant task, which consequently leads to better student achievement scores [36]. As Thanachawengsakul and Wannapiroon stated, it is important to encourage online participation in order to provide online learning [37].

The present study showed that integrating gamification elements in the flipped classroom pre-class phase had a positive effect on the students' online participation and achievement.

\section{Limitations and future research}

This study, as with any other empirical study, has certain limitations. Firstly, only quantitative data were used in the study. Future studies can be conducted by doing further analysis using qualitative data collection tools. Secondly, the participants of this study only comprised of students who were studying in a private university. Thus, the results cannot be generalized nationally. The study can be conducted with students from public universities and with more participants. Thirdly, in order to prevent student interactions in the distance learning processes, separate classes were created in Moodle for the experimental and control groups. However, the interaction between the group members was not analysed. These student interactions can be analysed in future studies. The most important challenge in conducting the research is that students have internet connection problems while working with pre-lesson materials or that there are no students who do not have internet.

The online learning enriched with gamification was realized through the Moodle platform. Although many gamification components can be used in Moodle, the gamification components used in the study are limited to Moodle's plugins. Finally, the findings of the research cannot be generalized to all courses in higher education. Therefore, to validate the findings of this study, we suggest conducting studies in the teaching of courses in different fields. Moreover, for future research, the impact of the applied model on academic and administrative staff can be examined. 


\section{$7 \quad$ References}

[1] M. W. N. Eugenia, "Integrating self-regulation principles with flipped learning pedagogy for first year university students”, Computers \& Education., vol 126, pp.65-74, https://doi. org/10.1016/j.compedu.2018.07.002

[2] G. M. Lundberg, B. R. Krogstie, and J. Krogstie, "Becoming Fully Operational: Employability and the Need for Training of Computer Science Graduates," EDUCON, pp. 644-651, 2020, https://doi.org/10.1109/educon45650.2020.9125188

[3] J. Kanelopoulos, K. A. Papanikolaou, and P. Zalimidis, "Flipping The Classroom to Increase Students' Engagement and Interaction in a Mechanical Engineering Course on Machine Design," iJEP, vol 7, pp.19-34, 2017, https://doi.org.10.39991/ijep.v7i4.7427

[4] C. K. Lo, and K. F. Hew, "A comparison of flipped learning with gamification, traditional learning, and online independent study: the effects on students' mathematics achievement and cognitive engagement", Interactive Learning Environments, vol. 28, no.2, pp. 464-481, 2018. https://doi.org/10.1080/10494820.2018.1541910

[5] G. J. Hwang, C. L. Lai, and S. Y. Wang, "Seamless flipped learning: a mobile technologyenhanced flipped learning with effective learning strategies", Journal of Computers in Education, vol. 2, no.4, pp. 449-473, 2015, https://doi.org/10.1007/s40692-015-0043-0

[6] C. J. Mortensen, and A. M. Nicholson, "The flipped classroom stimulates greater learning and is a modern 21 st century approach to teaching today's undergraduates", Journal of animal science, vol.93, no.7, pp. 3722-3731, 2015. https://doi.org/10.2527/jas.2015-9087

[7] J. M. Fautch, "The flipped classroom for teaching organic chemistry in small classes: is it effective?”, Chemistry Education Research and Practice, vol. 16, no.1, pp. 179-186, 2015. https://doi.org/10.1039/c4rp00230j

[8] E. C. Turner, "Measuring learning outcomes and attitudes in a flipped introductory statistics course", Primus, vol. 25, no. 9-10, pp. 833-846, 2015, https://doi.org/10.1080/10511970. $\underline{2015.1046004}$

[9] S. Papadakis, and M. Kalogiannakis, "Using gamification for supporting an introductory programming course the case of classcraft in a secondary education classroom. The Case of ClassCraft in a Secondary Education Classroom.”, Lecture Notes of the Institute for Computer Sciences, Social Informatics and Telecommunications Engineering, pp. 366-375, https://doi.org/10.1007/978-3-319-76908-0_35

[10] S. Deterding, D. Dixon, R. Khaled, and L. Nacke, "From game design elements to gamefulness: defining" gamification", In Proceedings of the 15th international academic MindTrek conference: Envisioning future media environments, New York, United States, September, 2011, pp. 9-15. https://doi.org/10.1145/2181037.2181040

[11] M. Tan, and K. F. Hew, "Incorporating meaningful gamification in a blended learning research methods class: Examining student learning, engagement, and affective outcomes", Australasian Journal of Educational Technology, vol. 32, no. 5, pp. 19-34, 2016, https://doi.org/10.14742/ajet.2232

[12] M. Sailer, and M. Sailer, "Gamification of in-class activities in flipped classroom lectures", British Journal of Educational Technology, vol. 52, no. 1, pp. 75-90, 2021, https://doi.org/10.1111/bjet.12948

[13] M. E. Parra-González, J. López Belmonte, A. Segura-Robles, and A. Fuentes Cabrera, “Active and emerging methodologies for ubiquitous education: Potentials of flipped learning and gamification", Sustainability, vol. 12, no. 2, pp. 602, 2020, https://doi.org/10.3390/ $\underline{\mathrm{su} 12020602}$

[14] K. M. Kapp, "The gamification of learning and instruction: game-based methods and strategies for training and education”, John Wiley \& Sons, 2012. 
Paper-The Effects of the Gamified Flipped Classroom Method on Petroleum Engineering Students'...

[15] J. Majuri, J. Koivisto, and J. Hamari, "Gamification of education and learning: A review of empirical literature", In Proceedings of the 2nd international GamiFIN conference, GamiFIN 2018. CEUR-WS, 2018.

[16] D. Dicheva, C. Dichev, G. Agre, and G. Angelova, "Gamification in education: A systematic mapping study”, Journal of Educational Technology \& Society, vol. 18, no. 3, pp. 75-88, 2015.

[17] K. Werbach, and D. Hunter, "The gamification toolkit: dynamics, mechanics, and components for the win", Wharton School Press, 2015.

S. Papadakis, "Evaluating a game-development approach to teach introductory programming concepts in secondary education", International Journal of Technology Enhanced Learning, vol.12, no.2, pp. 127-14, 2020, https://doi.org/10.1504/IJTEL.2020.106282

[19] K. Puritat, "Enhanced Knowledge and Engagement of Students Through the Gamification Concept of Game Elements", International Journal of Engineering Pedagogy, vol.9, no.5, 2019, https://doi.org/10.3991/ijep.v9i5.11028

[20] M. Böckle, J. Novak, and M. Bick, "Towards adaptive gamification: a synthesis of current developments" In Proceedings of the 25th European Conference on Information Systems (ECIS), Guimarães, Portugal, June 5-10, 2017. https://aisel.aisnet.org/ecis2017_rp/11

[21] B. Gil, I. Cantador, and A. Marczewski, “Validating gamification mechanics and player types in an e-learning environment", In Design for Teaching and Learning in a Networked World , pp. 568-572, Springer, Cham., 2015. https://doi.org/10.1007/978-3-319-24258$\underline{3} 61$

[22] C. Latulipe, N. B. Long, and C.E. Seminario, "Structuring flipped classes with lightweight teams and gamification", In Proceedings of the 46th ACM Technical Symposium on Computer Science Education, February 2015, Kansas City, Missouri, USA: 392-397, 2015, https://doi.org/10.1145/2676723.2677240

[23] H. T. Hung, "The integration of a student response system in flipped classrooms", Language Learning \& Technology, vol.21, no.1, pp. 16-27, 2017 https://scholarspace.manoa.hawaii.edu/bitstream/10125/44593/21_01_hung.pdf

[24] I. Yildirim, "The effects of gamification-based teaching practices on student achievement and students' attitudes toward lessons", The Internet and Higher Education, vol. 33, pp.8692, 2017, https://doi.org/10.1016/j.iheduc.2017.02.002

[25] S. Measles, and S. Abu-Dawood, S., "Gamification: Game-based methods and strategies to increase engagement and motivation within an elearning environment", In Society for Information Technology \& Teacher Education International Conference, onference 2015 March, pp. 809-814. Association for the Advancement of Computing in Education (AACE), 2015.

[26] A. Marczewski, "Even Ninja Monkeys like to play", London: Blurb Inc, 2015. https://www.gamified.uk/wp-content/uploads/2018/10/Narrative-Chapter.pdf, 2015

[27] K. Werbach, and D. Hunter, "For the win: How game thinking can revolutionize your business", Wharton digital press, 2012.

[28] G. Zichermann, and C. Cunningham, "Gamification by design: Implementing game mechanics in web and mobile apps", O'Reilly Media, Inc., 2011.

[29] E. Demertzi, N. Voukelatos, Y. Papagerasimou, and A. S. Drigas, "Online learning facilities to support coding and robotics courses for youth, "International Journal of Engineering Pedagogy (iJEP), vol.8, no.3, pp.69-80, 2018. https://doi.org/10.3991/ijep.v8i3.8044

[30] B. Huang, K.F. Hew, and P. Warning, "Engaging Learners in a Flipped Information Science Course with Gamification:A Quasi- experimental Study", In International Conference on Technology in Education (ICTE) 2018 January 9-11, Hong Kong China:30-141. Springer, 2018. https://doi.org/10.1007/978-981-13-0008-0 13 
Paper-The Effects of the Gamified Flipped Classroom Method on Petroleum Engineering Students'..

[31] D. Robinson, and V. Bellotti, "A preliminary taxonomy of gamification elements for varying anticipated commitment", CHI 2013 April 27-May 2, Workshop on Designing Gamification: Creating Gameful and Playful Experiences, Paris: ACM., 2013. https://doi.org/ $\underline{10.1145 / 2468356.2479662}$

[32] M. D. Hanus, and J. Fox, "Assessing the effects of gamification in the classroom: A longitudinal study on intrinsic motivation, social comparison, satisfaction, effort, and academic performance", Computers \& education, vol. 80, pp. 152-161, 2015, https://doi.org/10.1016/j.compedu.2014.08.019

[33] G. Barata, S. Gama, J. Jorge, and D. Gonçalves, "Gamification for smarter learning: tales from the trenches", Smart Learning Environments, vol.2, no. 1, pp.1-23, 2015. https://doi.org/10.1186/s40561-015-0017-8

[34] A. Amriani, A. F. Aji, A.Y. Utomo, and K.M. Junus, "An empirical study of gamification impact on e-Learning environment, InProceedings of 2013 3rd international conference on computer science and network technology 2013 Oct 12, pp. 265-269, IEEE. https://doi.org $\underline{/ 10.1109 / \text { iccsnt.2013.6967110 }}$

[35] M. Kalogiannakis, S. Papadakis, and A-I. Zourmpakis, "Gamification in Science Education. A Systematic Review of the Literature", Education Sciences, vol.11, no.1, 22, 2021. https://doi.org/10.3390/educsci11010022

[36] R. N. Landers, "Developing a theory of gamified learning: Linking serious games and gamification of learning", Simulation \& Gaming, vol.45, no.6, pp.752-768, 2014 https://doi.org/10.1177/1046878114563660

[37] N. Thanachawengsakul, and Wannapiroon, P., "Development of a Learning Ecosystem Using Digital Knowledge Engineering Through MOOCs Knowledge Repository System”, International Journal of Engineering Pedagogy (iJEP), vol.11, no.1, pp.35-48, 2021. https://doi.org/10.3991/ijep.v11i1.15011

\section{Authors}

Gulsum Asiksoy completed her BSc degree at the Ankara University Physics Engineering Department and her MSc degree in the field of Electrical-Electronic Engineering. She obtained her PhD. degree at the Near East University Computer Technologies Department. Assoc. Prof. Dr. Asiksoy has published articles and books in the Sciences and Social Sciences indices in the fields of flipped learning, games in learning and teaching, interactive simulation in teaching physics, digital games-simulations.

Serhat Canbolat is a full time Assist.Prof.Dr. in Petroleum and Natural Gas Engineering in Department of Near East University Nicosia/TRNC. He got his BSc., MSc. and PhD. degrees from Middle East Technical University, Department of Petroleum and Natural Gas Engineering and $2^{\text {nd }}$ MSc from University of Alberta, School of Mining and Petroleum Engineering, Edmonton/Canada.

Article submitted 2021-02-11. Resubmitted 2021-06-10. Final acceptance 2021-06-10. Final version published as submitted by the authors. 